\title{
Travel Risks and Preventive Strategies: An Overview
}

\author{
Mohsen Saberi Isfeedvajani, ${ }^{1,}$ \\ ${ }^{1}$ Medicine, Quran and Hadith Research Center \& Department of Community Medicine, Faculty of Medicine, Baqiyatallah University of \\ Medical Sciences, Tehran, IR Iran
}

*Corresponding Author: Mohsen Saberi Isfeedvajani, MD, Assistant Professor, Department of Community Medicine, Faculty of Medicine, Baqiyatallah University of Medical Sciences, Shahid Nosrati Dead End, Sheik Bahaei Ave, Molla Sadra Ave, Tehran, Iran. Tel: +98-02181263617, Email: drsaberihaji@gmail.com

Article History: Received: 20 Mar. 2015; Accepted: 7 Apr. 2016; Online Published: 25 Jun. 2016

Cite this article as: Saberi Isfeedvajani M. Travel risks and preventive strategies: an overview. Int J Travel Med Glob Health. 2016;4(2):39. doi: 10.20286/ijtmgh-04021

Travel health risks are primarily classified as infectious or non-infectious. Travel-related risks vary according to traveler factors, destination factors, type and reason of travel, duration of travel, accommodations, and budget [1, 2]. Although infectious disease mortality is estimated to be less than $1 \%$ of deaths during travel, infection with lethal diseases such as malaria occurs due to lack of effective preventive services before travel. Also, the risk of infectious disease is higher for those who travel to developing countries [1].

Many overseas deaths are due to natural causes, with cardiovascular disease being the most common cause $[1,3]$. Traffic accidents are estimated to be the most common cause of death among travelers to developing countries [4]. It is clear that evaluation of underlying medical conditions in travelers and providing preventive strategies can reduce potential harm (morbidity or mortality) to travelers $[1,3]$. The following underling diseases are important to identify and address: asthma, diabetes, immunocompromised states such as HIV infection, predisposition to deep venous thrombosis (DVT), blood disorders, and asplenia [1].

Travel-related infectious disease prevention strategies have been described in textbooks [1] and by the Center for Disease Control [5]. Unfortunately, travelers do not seek pre-travel health advice and the health system ignores it [3, 6]. Many factors play a role in disease acquisition by travelers and its prevention. Behavioral factors play a crucial role. These include poor insight to behaviors such as food habits, vaccinations, and prophylaxis $[1,3,6]$.

Another factor affecting disease acquisition and prevention is the destination. For example, the risk of malaria is higher in malaria-endemic areas such as sub-Saharan Africa [1]. The type of and reason for travel are other factors. The risk to business travelers is usually less than to other travelers; however, the risk varies according to the activities carried out. Business travelers may be at risk for low back pain or other musculoskeletal complaints from frequent air travel. Poor health literacy of immigrants expose them to higher risk when staying with local families because they do eat selectively or heed advice about preventable disease $[1,2]$.
A pre-travel preventive strategic approach is necessary to reduce travel risk. This approach includes a comprehensive medical history and a medical examination. Individualized preventive strategies such as vaccinations, drug prophylaxis and medications, and pre-travel advice should be provide based on these factors. It is highly recommended that pretravel assessment and advice should be carried out 6 to 12 weeks prior to travel $[1,2]$.

\section{Acknowledgments}

The author would like to thank the Clinical Research Development Unit of Baqiyatallah Hospital for their kind cooperation.

\section{Financial Disclosure}

Not declare.

\section{Funding/Support}

Not declare.

\section{References}

1. Lang RS, Hensrud DD. Clinical preventive medicine: AMA Press; 2004.

2. Leder K, Steffen R, Cramer JP, Greenaway C. Risk assessment in Travel medicine: how to obtain, interpret, and use risk data for informing pre-travel advice. J Travel Med. 2015;22(1):13-20. doi: $10.1111 / \mathrm{jtm} .12170$

3. Gagneux-Brunon A, Andrillat C, Fouilloux P, Daoud F, Defontaine C, Charles R, et al. Pre-travel advice seeking from GPs by travellers with chronic illness seen at a travel clinic. J Travel Med. 2016;23(3). pii: taw013. doi: 10.1093/jtm/taw013

4. Stewart BT, Yankson IK, Afukaar F, Medina MCH, Cuong PV, Mock C. Road traffic and other unintentional injuries among travelers to developing countries. Med Clin North Am. 2016;100(2):331-43. doi: 10.1016/j.mcna.2015.07.011

5. Stoney RJ, Chen LH, Jentes ES, Wilson ME, Han PV, Benoit $\mathrm{CM}$, et al. Malaria prevention strategies: adherence among Boston area travelers visiting malaria-endemic countries. Am J Trop Med Hyg. 2016;94(1):136-42. doi: 10.4269/ajtmh.150565

6. Ismayl G, Hadi HA, Hussein A, Balchi M, Hukan Y, Mohamed M, et al. Practices and attitudes to prevention of travel-related infectious diseases in United Arab Emirates. Int J Travel Med Glob Health. 2016;4(1):13-8. doi: 10.20286/ijtmgh-040113 